\title{
Effects of Constructivist Approach on Students' Perception of Nature of Science at Secondary Level
}

K V Sridevi*

\begin{abstract}
A quasi-experimental study was conducted to see whether constructivist approach to science instruction could promote perception of nature of science among eighth grade students. Purposive sampling was employed to select the schools for the study. Perception of nature of science test was developed by the researcher and was administered before and after the treatment. Analysis of Covariance test was performed to control the initial variance. The results showed that Constructivist teaching is more effective than conventional teaching in terms of perception of nature of Science among $8^{\text {th }}$ standard students. It was also found that constructivist approach was equally effective for both boys and girls in improving achievement and attitude towards science. A constructivist environment was preferred to a traditional classroom by the students. The results confirm research supporting the positive effect of constructivist learning practices and view that constructivist approach to teach science is a viable alternative to traditional modes of teaching.
\end{abstract}

Keywords: Constructivist Approach; Perception of nature of science; Variance

* Lecturer in Education, Amrita of Education, Mysore, Karnataka; kvsridevi@gmail.com 


\section{Introduction}

\section{Nature of Science and Science Teaching}

Conant (1951), an eminent scientist and an educator defined science as "an interconnected series of concepts and conceptual schemes that have developed as a result of experimentation and observation and are fruitful to further experimentation and observation".

Science as an enterprise has individual, social, and institutional dimensions. It is fundamentally a means of understanding why things happen as they do. Man has found science as a process by which his search for answers to his unlimited questions can be approached systematically. In this way the study of science is an intellectual and social endeavour. The application of human intelligence in figuring out how the world works should have a prominent place in any curriculum that has science literacy as one of its aims.

Bullock (1976), a historian has deemed science to be 'the greatest intellectual and cultural achievement of modern man'. He perceived science as an open-ended process in which imagination, hypothesis, criticism and controversy take a dominant role. It is not, nor was it ever, 'the closed dogmatic system of immutable laws beloved of 19th century positivists'. Bullock sees science as a humane activity, deeply concerned with man and society, providing scope for imagination and compassion as well as for observation and analysis.

Science thus, is simultaneously a body of knowledge and a way of gaining and using that knowledge. The accumulated and systematized body of knowledge is the 'product' of science. It has a dynamic counterpart, the scientific attitudes and methods of inquiry, which is the 'process' of science. Science thus is a combination of both 'processes' and 'product' related to and dependent upon each other. When, used in this way, science offers methods of inquiry useful in learning more about the universe and its workings. 
The processes of science include scientific attitudes and methods of inquiry. Scientific attitudes include both emotional attitudes such as curiosity, humility, determination and open mindedness; and intellectual attitudes namely objectivity, scepticism and rationality. The methods of inquiry are observing, hypothesizing, analyzing, inferring, extrapolating, reasoning, synthesizing etc. The scientific attitudes develop simultaneously with science process skill development and with the discovery or construction of useful science ideas. The information and ideas of science that compose its knowledge base are often referred to as 'products' since new discoveries add to the base of scientific information which are the products of curiosity and experimentation. An interesting thing about science knowledge is that new discoveries often lead to more questions, more experiments, and further discoveries. The science cycle moves under its own momentum propelled initially and again later sustained by human curiosity and a desire to explain natural phenomena. The effect is an exploding accumulation of new information that is added to the knowledge base. Scientific knowledge consists of primarily facts, concepts, principles and theories. The scientific theories are refined in the light of new ideas which Kuhn (1970) called a new paradigm.

It is a well known fact that children are curious. Their curiosity motivates them to discover new ways to use this powerful key for unlocking the mysteries of their world. As said earlier both the products and processes for acquiring them are to be experienced by the students. Children receive a wholesome experience when they are immersed in all the three parts of science. The synergy among the parts makes science a whole.

Apart from the knowledge and attitudes, there is one more part of science i.e. science process skills. Children learn by thinking critically and using information creatively. They continue to learn how to make discriminating observations, when organizing and analysing facts and concepts, when giving reasons for expected outcomes, when evaluating and interpreting the results of experiments and when drawing justifiable conclusions (Victor, 1985). In science, the ways of thinking, measuring, solving problems and using thoughts are called process skills. Process skills describe the type of thinking and reasoning required. 
Science process skills along with science related attitudes lead to discovery of scientific knowledge that is the product side of science. Scientific knowledge is tentative. A scientific finding or a prediction, which is accepted to be true at a particular time, is probabilistic and not absolute. It is derived from imagination, observation and experimentation. Scientific knowledge is rational and empirical i.e. it has its origin in the real world, and dependent on sense experiences. It is holistic; the knowledge gathered by various branches of science contributes to an overall conceptual scheme or mental construct, which is internally consistent. As a product of creative human imagination, concepts of science reflect the social and cultural background of their times. The values that underlie science represent the very human origin itself. It can be argued that without these values, the enterprise of science could not have occurred. They are,

- Consideration of consequences - decision based on the assessment of the effects emanating from an action or a set of actions.

- Longing to know and understand.

- Demand for verification - search for supporting evidence to verify the validity and accuracy of a statement.

- Questioning - belief that all things, including "self-evident" truths are open to question.

- Respect for logic - consideration of influences that emerge from cause-effect relationships.

- Search for data and their meanings.

Learning of science in schools augments the spirit of enquiry, creativity and objectivity along with aesthetic sensibility. It aims to develop well-defined abilities of knowing, doing and being. It also nurtures the ability to explore and seek solution of the problems related to the environment and daily life situations and to question the existing beliefs, prejudices and practices in society. Thus science is must for every child to learn as it gives an opportunity to learn how to learn. 


\section{Constructivism and Science Teaching}

Constructivism is not a new concept. It is learning or meaning making theory. It suggests that individuals create their own understanding, based upon the interaction of what they already know and believe and the phenomena or ideas with which they come into contact. According to Crowther (1997), constructivism means that, "as we experience something new we internalize it through our past experiences or knowledge constructs that we have previously established." Constructivism bristles with philosophical questions: it explicitly assumes positions in the philosophy of science, the philosophy of mind, and the philosophy of education. It is at once a theory of science, of human learning and of teaching.

Constructivism according to Piaget (1971) is a system of explanations of how learners, as individuals adapt and refine knowledge. In this view learners actively restructure knowledge in highly individualized ways, basing fluid intellectual configurations on existing knowledge and formal instructional experiences. Piaget focused that the individual is the sole agent in the process of constructing and reconstructing meaning. Psychological constructivism is based on Jean Piaget's model of development of the individual. The process focuses learning as a personal, individual, intellectual construction based on experiences of one in the world.

Learning by doing and forming ideas from exploration is the underlying theory behind psychological constructivism. The child is viewed like a scientist who possesses insights, questions, problem solving strategies and new ideas that will be used in experimentation. The scientific process of puzzling, probing, testing are incorporated into the approach. The child develops his picture or understanding of the physical world through manipulation and seeing relationships between objects and learning centrally determined names and labels for the ideas, items and activities involved through experience. Key to the theory is fostering independence in the child, not dependence on adults so that activities, curriculum, environment are based on risk-taking, 
self-direction, guided or totally free discovery type experimentation through social interaction and problem solving. The teacher acts as a facilitator of the educational context. The teacher provides opportunities for observation, interaction of students with each other and with the teacher through questioning techniques, modifying the environment, and support during conflicts and planning and creating curriculum.

\section{Role of Constructivist Approach in Science Classroom}

A constructivist learning setting differs from the one based on the traditional model. In a constructivist classroom, learning outcomes not only depend on the learning environment but also on the knowledge of the learner. Learning involving the construction of meanings by students from what they see or hear may or may not be those intended. It is a continuous and an active process, which is influenced to a large extent by existing knowledge. Firstly current ideas of pupils are elicited using several strategies. These include pupils writing, expressing orally, card-sorting exercises, presenting pupils with descriptions of events and asking them to decide whether they are true or false, and pupils producing posters on a particular idea. In this regard Driver et al., (1994) identified five possible forms, depending on the outcome of the elicitation phase. These are:

- Developing existing ideas (if no misunderstandings are apparent);

- Differentiating between existing ideas (where two or more scientific ideas may be seen as one by pupils, e.g. dissolving and melting);

- Integrating existing ideas (where pupils may hold several ideas relating to one scientific ideas);

- Changing existing ideas (where pupils hold ideas which differ from the scientifically accepted ideas); and

- Introducing new ideas

After elicitation phase, the most difficult thing is changing existing ideas. Among the various methods, the most prominent ones are 
Socratic questioning and introducing discrepant events in order to induce cognitive conflict, disequilibrium or dissonance in the minds of pupils. These approaches will help in the modification of existing ideas and in construction of new ideas. After the evaluation of the ideas, they are applied in new situations. Later the new idea is compared with previous ideas. Thus meanings, once constructed, are evaluated and can be accepted or rejected. Learners take the final responsibility of their learning (Driver \& Bell, 1986).

Various educators and cognitive psychologists have applied constructivism to the development of learning environments. Brooks and Brooks (1993) offered an interesting comparison of the visible differences between "traditional" classroom and "constructivist" classrooms. Their comparison is as follows:

- Students primarily work in groups unlike individually as in traditional classroom.

- Curriculum is presented whole to part with emphasis on the big concept whereas in traditional classroom it is vice versa.

- Pursuit of student questions is highly valued whereas in traditional classroom strict adherence to a fixed curriculum is valued.

- Curricular activities rely heavily on primary resources unlike relying only on text books.

- Students are viewed as thinkers with emerging theories about the world (Cognitive apprentices) unlike its counterpart.

- Teachers are information dispensers and assess only to validate student lessons in traditional classroom where as a constructivist teacher generally behaves in an interactive manner mediating the environment for students and seeks student's point of view in order to understand student learning for use in subsequent conceptions. 
It is understood from the above description that constructivism unlike the conventional method of teaching involves exploration of students' pre-existing ideas and their construction or reconstruction accordingly using various child cantered strategies of teaching. The student autonomy and initiative are accepted and encouraged in the classroom. Thus this innovative approach will result not only in developing cognitive abilities but also in modifying attitudes, increase self-confidence and decision making ability among the students.

At the national level, National Curriculum Framework for School Education, 2000 brought out by the National Council of Educational Research and Training (NCERT) emphasized viewing the child as a constructor of knowledge. Learning of science up to secondary stage needs to be replaced by learning of science and technology in view of strong organic linkages between the two. It also recommended the following:

- Scientific attitudes and skills should be developed.

- Students need to be exposed to the nature and structure of science and the support it provides to the technological developments.

- Learning of science would be built around natural and social elements of environment.

- Focus would be on understanding of concepts and applications in the areas of matter and its properties, energy, relationship of various physical processes and the technological applications of principles of science.

- Science, technology, society and environment would coalesce in teaching and learning of science at secondary stage.

- Practical activities chosen should have relevance for further life through acquisition of skills and values.

- Critical, creative and generative thinking has to be developed. 
- Improvisation should be encouraged but designing would also be provided as a component in exploration.

- Flexibility in experimentation needs to be widely promoted.

- Teachers could help the learners devise appropriate experimentation activities within and outside the school.

All the above ideas and processes occur repeatedly in constructivist writings. Even the students who score well are unable to successfully integrate or contrast memorized facts and formulate real-life applications outside the school - room (Yager, 1991). It was also found that practical knowledge and school knowledge are becoming mutually exclusive. Many students see little connection between what they learn in the classroom and with their real life. One proposed solution for the problem is to prepare students to become good adaptive learners. An attempt was made to study the effectiveness of constructivist approach in the Indian context at secondary school level to find out whether this method would improve the students' understanding of nature of science and demonstrate a superior understanding of basic science concepts

\section{Objectives of the Study}

1. To develop science lessons based on constructivist approach in the selected units of science for eighth standard students.

2. To study the effectiveness of constructivist approach on the students' perception of nature of science.

3. To study the interaction between 'gender' and 'group' with reference to perception of nature of science at secondary school level.

\section{Method}

The present investigation was carried out to study the effectiveness of constructivist approach on science related variables. The design adopted in the study was quasi-experimental. Non-equivalent control group design was adopted in the present study, which is similar to the pre-test-post-test control group design except for the 
absence of the random selection of students from a population and random assignment of the students to the experiment and control groups. All the measures were undertaken to reduce differential selection and experimental mortality, which are the two main threats of the design. The study was conducted in two schools of Mysore city, that were selected based on their common features like syllabus followed and type of the school. As the experiment required the whole class as such, this design was chosen.

\section{Sample for the Study}

The intact groups of 68 students of eighth standard including, both experimental and control group were taken up for the study. The sample included 37 boys and 31 girls in total. The experimental group consisted of 36 eighth standard students, of which were 21 boys and 15 girls and the control or alternate group consisted of 32 eighth standard students, which included 16 boys and 16 girls.

\section{Instrumentation}

Ravens Progressive Matrices was used to find out the general mental ability of the selected sample of the students.

\section{Perception of Nature of Science Test}

Perception of nature of science test was developed to know the perceptions of students on nature of science pertaining to the following aspects:

- Characteristics of Science

- Scientific methods/processes

- Use of scientific discoveries

- Application of science in daily life

- Role of science in society and its impact on human beings.

There are 26 items in the test assessing the students' perceptions on the above dimensions of nature of science. Through the analysis of the data collected by test retest method, it was found that the correlation coefficient was $(r=0.70)$ which indicated the high reliability of the test. 


\section{Reaction Scale}

A reaction scale was constructed in order to know the reactions of pupils towards constructivist approach adopted in teaching science. It consisted of four main components namely; the method used, the classroom atmosphere, his role of teacher, and the evaluation techniques used during intervention.

\section{Semi Structured Interview}

Interviews were taken to elicit the views of students on the technique of teaching using constructivist approach, classroom climate, role of teacher and evaluation techniques.

\section{Administration of Pre-Tests}

The tools were administered to the students of both the experimental and control groups as a pre-test i.e. before treatment. The students of both the experimental and control groups were simultaneously pre-tested on Ravens progressive matrices and perception of nature of science test one by one.

\section{Implementation of Experiment}

In the present study, planning and learning cycle, 4Es model was used. The four Es indicate Exploration, Explanation, Expansion and Evaluation. In the first stage, Explore, the students first encounter and identify the instructional task. Here they make connections between past and present learning experiences, lay the organizational ground work for the activities ahead and stimulate their involvement in the anticipation of these activities. The students have the opportunity to get directly involved with phenomena and materials. Involving themselves in the activities along with others, students build a base of common experience, which assist them in the process of sharing and communicating. The student observes, identifies, classifies etc in this phase.

In the second stage, Explain, is the point at which the learner begins to put the abstract experience through which he or she has gone/into a communicable form. Communication occurs between peers, the facilitator or within the learner himself. 
In stage three, Expand, the students expand on the concepts they have learned, make connections to other related concepts and apply their understandings to the world around them.

And lastly Evaluate, the fourth " $\mathrm{E}$ ", is an on-going diagnostic process that allows the teacher to determine if the learner has attained understanding of the concepts and knowledge. Evaluation and assessment can occur at all points along the continuum of the instructional process.

The instructional materials based on 4E Model were developed and implemented to the experimental group for a period of four months. Consulting the science teacher of control group the duration i.e. number of periods required for teaching the selected lessons was decided. The investigator taught seven units using constructivist approach to the experimental group. Classes were taken in the regular science periods of the school. It was ascertained that the regular science teacher covered the units approximately in the same number of periods using alternative strategies like lecture method, used charts, etc. for the other group. In the present study alternative strategy is referred to control group. The investigator got continuous feedback from the experimental group students and their regular teachers. The lessons were also audio recorded which added up to the feedback. The unit test was given as soon as each lesson was completed apart from daily assignments.

\section{Administration of Post-tests}

After the completion of the treatment both the experimental and control group were post tested on perception of nature of science test. The students of experimental group were given a reaction scale and interviews were conducted to add the qualitative information in the study.

\section{Statistical Treatment of the Data}

The experimental design chosen had no control over the pre-test differences between control and experimental groups. Thus to control the initial differences, analysis of covariance test was employed. Both the pre-test scores and intelligence were taken as covariates. 
In pursuance of the second and third objectives, to study the effect of constructivist approach on the achievement in science of students, the following hypotheses were formulated:

H1: The constructivist approach does have a positive effect on the students' perception of nature of science.

$\mathrm{H} 2$ : There is no significant difference in the students' perception of nature of science between boys and girls as an effect of constructivist approach.

H3: There is no significant interaction between 'gender' and 'groups' with reference to perception of nature of science of students.

To test the above hypotheses, analysis of covariance test was employed. The results of analysis of covariance test for testing the above hypotheses are summarized in the following tables:

Table 1: Mean Scores of Girls and Boys of Experimental and Control Groups on Perception of Nature of Science Test

\begin{tabular}{|l|l|l|l|l|l|}
\hline \multirow{2}{*}{ Group } & \multirow{2}{*}{ Gender } & \multirow{2}{*}{$\mathbf{N}$} & \multicolumn{2}{|c|}{ Mean scores } & \multirow{2}{*}{ Change } \\
\cline { 4 - 6 } & & & Pre-test & Post-test & \\
\hline \multirow{3}{*}{ Experimental } & Girls & 15 & 15.80 & 21.27 & +5.47 \\
\cline { 2 - 5 } & Boys & 21 & 14.33 & 20.76 & +6.43 \\
\cline { 2 - 6 } & Total & 36 & 14.94 & 20.97 & +6.03 \\
\hline \multirow{3}{*}{ Control } & Girls & 15 & 13.67 & 16.67 & +3.00 \\
\cline { 2 - 5 } & Boys & 17 & 14.94 & 15.94 & +1.00 \\
\cline { 2 - 5 } & Total & 32 & 14.34 & 16.28 & +1.94 \\
\hline
\end{tabular}

The mean score of the experimental group on perception of nature of science test (20.97) is found to be significantly higher than the control group (16.28) as shown in the table.1. The change of scores from pre-test to post-test were 6.03 and 1.94 for experimental and control groups respectively.

A large amount of change was observed in the experimental group, which can be attributed to effectiveness of experimental treatment. 
Table 2: Results of Analysis of Covariance: Tests of Between-Subjects Effects with Respect to Achievement in Science.

\begin{tabular}{|l|r|r|r|r|r|}
\hline \multicolumn{1}{|c|}{ Source of variation } & \multicolumn{1}{c|}{$\begin{array}{c}\text { Sum of } \\
\text { squares }\end{array}$} & df & \multicolumn{1}{c|}{$\begin{array}{c}\text { Mean } \\
\text { square }\end{array}$} & \multicolumn{1}{c|}{ F } & Sig \\
\hline $\begin{array}{l}\text { Pre perception of nature } \\
\text { of science }\end{array}$ & 291.194 & 1 & 291.194 & 38.712 & .000 \\
\hline Intelligence & 62.975 & 1 & 62.975 & 8.372 & .005 \\
\hline Group (A) & 337.696 & 1 & 337.696 & 44.894 & .000 \\
\hline Gender (B) & 6.361 & 1 & 6.361 & 1.244 & .269 \\
\hline Group*Gender (A*B) & 12.199 & 1 & 12.199 & 1.622 & .208 \\
\hline Error & 466.372 & 62 & 7.522 & & \\
\hline Total & 25322.00 & 68 & & & \\
\hline Corrected Total & 1378.235 & 67 & & & \\
\hline
\end{tabular}

Dependent variable: Post perception of nature of science

Analysis of covariance revealed a significant difference in the pretest scores of perception of nature of science $(\mathrm{F}=38.712$; $\mathrm{P}<0.00)$. After the treatment, a highly significant difference was observed ( $F$ $=44.894 ; \mathrm{P}<0.00)$ between the experimental group and control group, where the mean score of the experimental group (20.97) was found to be higher than the control group (16.28) as shown in the table 2 . The change of scores from pre-test to post test in perception of nature of science test was 6.03 and 1.94 for experimental and control groups respectively. The high positive change in the perceptions of the students belonging to experimental group can be attributed to the effectiveness of the constructivist approach. Thus the hypothesis 1 was retained. This finding is concomitant with the findings of Blunck and Yager (1990), which also evidenced that students in classes taught with a constructivist approach improved more in their understanding of the nature of science when compared to students in classes taught with a textbook oriented approach. Adams (1997) in his study found that the students taught by constructivist model were found to have perceived science as a relevant and useful to every day experience and also appreciated the importance of empirical evidence.

Between sexes, a non-significant difference was observed ( $\mathrm{F}=1.244$; $\mathrm{P}<0.269$ ). Hence the hypothesis 2 was rejected. Analysis of covariance also revealed a non-significant interaction between group and gender on perception of nature of science $(\mathrm{F}=1.622$; $\mathrm{P}<0.208)$. Hence the hypothesis 3 was rejected. 
Over all constructivist approach was found to be an effective method in building up better perceptions of nature of science. Some of the students who underwent this innovation expressed:

"We had a variety of experiences like participating in role plays, conducting experiments in the lab, field trips. This had helped us in taking up the role of a scientist and in knowing what science is? What are its characteristics? How a scientific method differs from the unscientific one? And so on. This method also gave us an opportunity to perform experiments by making use of scientific method. We had performed experiments repeatedly till we got correct answer. Especially when we took the role of a scientist and acted accordingly, we could feel the dedication, seriousness and patience of a scientist. This experience helped us not only in knowing about the discoveries and inventions but also in knowing the characteristics of scientists and their method of study".

\section{Major Findings of the Study}

1. Constructivist approach was found effective in improving the students' perception of nature of science.

2. Constructivist approach was found equally effective for both boys and girls in improving the students' perception of nature of science.

3. There is no significant interaction between 'gender' and 'groups' on the students' perception of nature of science.

\section{Educational Implications}

This study highlights the shift from teacher centred to learner centred classrooms wherein the students are given complete freedom to explore and discover things on their own. The role of a teacher is that of a facilitator and guide. This study could be very useful to teachers in creating innovative classroom situations where in the students are meaning makers which is the ultimate aim of learning.

The constructivist approach is an effective method in building up better perception of nature of science among the students, which is one of the main objectives of science education. Thus this study throws light on the importance of perception of nature of science 
among the students and the role of teacher in enhancing it. Hence, school management along with the teachers should provide opportunities to the students in understanding science.

This study also gives a picture of an innovative and democratic classroom where in the priority is given to the students' autonomy and the relationship between students and teacher and among the students. It was revealed that the students have really enjoyed the classroom experience and also felt that this method was not at all stressful. This study paved a pathway for a healthy classroom, which led to healthy relationship among the students and also with the teacher.

This also highlights the need to bring out change in pre-service teacher education programmes. The change in the perception of learners, learning process, evaluation etc. among teacher trainees has to be encouraged. Thus training programmes on constructivist approach could be organized for pre-service and in-service teachers so as to develop an understanding and the necessary skills for the successful implementation of the model in the classroom situations.

\section{Conclusion}

The word 'constructivism' has become a watchword among the researchers and teachers. The present study proved the effectiveness of this approach and new way of looking at things. Classrooms in future will encourage meaning makers than memorizers.

\section{References}

Adams, A. D. (1997). Students' beliefs, attitudes and conceptual change in a traditional and constructivistic high school physics classroom. Dissertation Abstracts International, 58(8), 3069-A.

American Association for the Advancement of Science.(1990). Science for all Americans. New York, NY: Oxford University Press.

Blunck, S. M. \& Yager, R. E. (1990). The Iowa Chautauqua program: A model for improving science in the elementary school. Journal of Elementary Science Education, 2(2), 3-9. 
Brooks J. G. \& Brooks M. G. (1993).In search of understanding: The case for constructivism classrooms. Alexandria VA: Association for Supervision and Curriculum Development.

Brooks, M. G. \& Brooks, J.C. (1999). The courage to be constructivist. Educational Leadership, 57(3).

Bullock, L. (1976), Presidential address to the A.S.E, School Science Review, 57 (201).

Conant, J. B. (1951).Science and Common Sense. New Haven: Yale University Press.

Crowther, D. T. (1997). Science experiences and attitudes of elementary education majors as they experience Biology 295: A multiple case study. Dissertation Abstracts International, 57(7), 2952-A.

Driver, R. \& Oldham, V. (1986).A constructivist approach to curriculum development in science. Studies in Science Education, 13, 105-122.

Driver, R., Asoko, H., Leach, J., Mortimer, E., \& Scott, P. (1994).Constructing scientific knowledge in the classroom. Educational Researcher, 23(7), 5-12. http:/ /dx.doi.org/10.3102/0013189X023007005

Fensham, P.J., Gunstone, R. F., \& White R. T. (Eds.).(1994). The content of science: A constructivist approach to its teaching and learning. Washington, D.C.: Falmer Press.

Kuhn, T. (1970).The Structure of Scientific Revolutions. Chicago, IL: University of Chicago.

Lynn, R. B. (1996). Developing a school assessment model from a constructivist perspective. Dissertation Abstracts International, 57(2), 521-A.

Matthews, M. R. (1993). Constructivism and science education: Some epistemological problems. Journal of Science Education and Technology, 2(1), 359-370. http:/ / dx.doi.org/10.1023/A:1021888323042

National Council for Teacher Education.(2009). National curriculum framework for teacher education, New Delhi.

National Council of Educational Research and Training.(2000). National curriculum framework for school education. New Delhi: Supreme Offset Printers.

National Council of Educational Research and Training.(2005). National curriculum framework for school education. New Delhi: Supreme Offset Printers. 
Piaget, J. \& Inhelder, B. (1971).Mental imagery in the child. New York, NY: Routledge \& Kegan Paul Limited.

Sherri, A. (1995). The effects of a constructivist-learning environment on student cognition of mechanics and attitude towards science: A case study. Dissertation Abstracts International, 56(8), 2981-A, 1996.

Shymansky, J. A., Yore, L.D., Treatgust, D. T., Thiele, R. B, Harrison, A., Waldrys, B.G., Stockmayer, S.M. \&Venville, G. (1997). Examining the constructivism process: A study of changes in level 10 students understanding of classical mechanics.Journal of Research in Science Teaching, 34, 571-593. http://dx.doi.org/ 10.1002/(SICI)10982736(199708)34:6

Shymansky, J. A., Yore, L. D. \& Anderson, J. O. (2000). A study of changes in students science attitudes, awareness and achievement across three years as a function of the level of implementation of interactiveconstructivist teaching strategies promoted in a local systemic effort. ERIC Document Reproduction Service: No. ED439954.

Sood, J. K. (1964). An investigation into the understanding of the nature of science among the national science talent search awardees, science teachers and the non-selected NSTS students. Indian Educational Review, 13(4), 138-143.

Turner, V. (1985). On the edge of the bush: Anthropology as experience. Tucson, AZ: University of Arizona Press.

Yager, R. E. (1991).The constructivist learning model towards real reform in science education. Science Teacher, 58, 52-57. 